\title{
Observation and Study of the Convicted Persons at the Penitentiary Institutions of the Republic of Macedonia
}

\author{
Mitasin Beqiri
}

FON University, Skopje, Docent

\section{Sevil Muaremoska}

FON University, Skopje, Assistant

\author{
Doi:10.5901/ajis.2015.v4n2s1p152
}

\begin{abstract}
Nowadays, it is rightfully considered that the issues regarding the selection and application of the tools and methods, which involve the individualized treatment and observation, are increasingly dealing within the realm of penology. This study will briefly review the more typical and current issues. Often, the term observation, when talking about general principles, relates to the knowledge of psychological, physical and social characteristics of the convict, but it also requires the application of specific tools and methods for each sanction, respectively, depending on their specific nature. Considering the most frequent sanction, which is imprisonment, as a usual measure to combat crime today, the greater focus is on its enforcement during imprisonment. Furthermore, not incidentally observation is identified precisely with this punishment. In relation to this, the clear definition of the term observation needs to be highlighted, as well as its elaboration regarding the specific ways of enforcement and effectuation of certain penal sanctions. In this context, the authors are rightfully stating that the treatment cannot (should not) be the same for intra-institutional and extra-institutional sentences. It is about essentially qualitative differences that require the enforcement of clear tools and methods, which are defined and differentiated in the re-socialization process.
\end{abstract}

\section{Understanding and Types of Observation and Study of Convicts}

One of the core prerequisites to obtain knowledge about convicts is their observation and study during their individualized treatment in the modern penal system. Observation deals with knowing the psychological, physical, social and other characteristics of the convicts. The personality of the convict should be observed and studied.

The observation and study of the convicts is done by various experts, who are usually specialized in criminology, psychology, sociology and the science of medicine.

The penology literature deals with two types of convicts' observation and study: the scientific observation and study, and the empirical observation and study (R. Mlagjenoviq- Kupqeviq, 2006).

\subsection{Scientific study and observation}

Scientific study and observation of convicts is carried out at specially established institutions for this purpose. This type of study and observation is done by a special team of experts specialized in various scientific fields. The institutions which carry out the scientific study and observation of convicts have different names, such as: criminology clinics, observation centers, classification centers, circulation centers, diagnostics centers, research and observation office, unlike the scientific study and observation.

\subsection{Empirical study and observation}

Empirical study and observation of convicts is carried out at penitentiary institutions, that is, penal and correctional institutes. This type of study and observation, too, is done by a team of experts, which is made of educators such as a social worker, a doctor, a psychologist, a penologist, an attorney, etc. Convicts are placed in separate facilities where they are observed and studied and those facilities are known as: reception offices, reception centers, classification centers, observation centers, etc. At these penitentiary facilities, convicts stay for a certain period of time, depending on the length of sentence and the relevant country. Some countries and their positive laws envisage a limited time from a 
month to a year, and some others do not put a time limit (Popoviç, 2003:171).

\section{The Study and Observation Method of Convicts}

The study and observation of convicts in the modern penitentiary system is conducted by modern tools and methods. The application of such tools and methods is interdisciplinary and of researching nature; it is related to familiarizing with the more specific and in-depth personality of the convict. Usually, the penology literature deals with the study and observation of convicts, which can be of psychosomatic or sociologic nature.

Psychosomatic study and observation include the state and anatomical and physical changes of the personality of convicts. These studies can be of biological, psychiatric and psychological nature, which aim at determining the anamnesis of the convict, that is, to take notes and gather data on the current health condition, on their medical background, on various different medical and surgical interventions of the convict, on possible family illnesses, laboratory and radiology data, $x$-rays, which determine the state and functioning of the body organs of the convict. All these are significant to determine the individualized treatment of the re-education process for the convicts.

Sociological study and observation deals with the study of the social and family conditions in which was formed the personality of the convict. More frequent methods and techniques that are applied in the study and observation of convicts are as follows: analysis of the social circumstances, psychoanalysis and narcoanalysis method, known tests, biometric method, surveys, interviews, conversation, analysis of certain circumstances, etc.

\subsection{Scope of observation and study of convicts}

The scope of observation and study of convicts deals with the fact whether or not all or several convicts should be involved in the observation and study process. It would be wise to include all persons in the observation and study process, since it would be completely possible to achieve their individualized treatment during their presence at the penitentiary institutions. In the modern penitentiary systems of many countries it is not possible to include all convicts in the observation and study process due to many reasons such as material and staff shortages Hence, another solution is imposed whether the category of convicts who should be observed and studied should be determined. In this context, there are different approaches, often contradicting, but two key conceptions are prevalent: the conception of optional observation and the conception of mandatory observation.

The optional observation deals with those convicts who show deviant symptoms and behavior of a greater intensity. On the other hand, the mandatory observation of convicts is compulsory for all convicts. This observation should be determined based on scientific and objective criterion. There are several views in the penology literature regarding the criterion on the assessment of convicts, who should be subject to the mandatory observation. The majority of authors share the belief that the following categories of persons should be involved in this type of observation: juveniles, long-term convicts, and the recidivists. In the penitentiary practice of many modern countries, these categories of convicts have to undergo the mandatory observation and study process due to the many attributes they have.

\subsection{Observation and study of convicts in the Republic of Macedonia}

The observation and study process of convicts in the Republic of Macedonia is led by the penal and correctional facilities. However, a type of empirical observation of convicts is set up, which, as is shown below, is still at a low level of organization unlike the level of organization in the penal and correctional facilities of many other countries.

Given the many circumstances of economic, social, political, cultural development, etc., and the data available, we can conclude that the scientific observation is not applied in the Republic of Macedonia. This is due to the lack of interest and functioning of the institutions and the lack of professional staff necessary to implement and find a genuine scientific study.

Empirical observation of convicts faces several difficulties and weaknesses in its practical implementation, therefore it can be said that the objective of this institution is not sufficiently attained. In the Republic of Macedonia, there are no observation centers for the analysis of convicts, but these are carried out at the reception units of the institutions (Kralev, 2002:175). At these units, the observation is done by psychologists, psychiatrists, etc., who are competent to observe the convicts and to confirm a diagnosis on their behavior and personality. The issue here is that the experts setting the diagnosis do not take part in the treatment of the convicts during their time in prison.

Consequently, in compliance with the penitentiary legal acts, immediately after their admission to the penal and 
correctional facility, the convicts undergo a procedure that is made up of a team of health experts, security guards, and the re-socialization and re-education experts (House rules of the Correctional Penitentiary Idrizovo, Article 37, p. 15). Additionally, the head of the health department or his deputy carries out a full physical and mental check-up of the convict and their ability to work. The head of the security unit or his/her subordinate informs the convict on the ground rules, his/her rights and duties: what they are allowed, what they are not allowed, their rights, fulfillment of their duties, the disciplinary measures in case of breach of regulations, etc. On the other hand, the head of the re-socialization and reeducation or the educator in charge informs the convict on the application of the most effective tools and methods of the treatment. Ditto, the convict's record is analyzed by the education service according to the identified methods in order to get familiar with his/her personality, to get familiar with his family and social setting, the crime they have committed, etc. During their stay at the reception unit, different research methods and techniques are applied, such as: surveys, interviews, conversations and other analyses, and in some cases tests are done and obtaining information whether or not they have any unresolved issues with the inmates. This is done for the sole purpose of avoiding any conflicts or disagreements with their actual arrival at the penal and correctional facility (Gashi, 2001:176).

According to Article 97 of the Law on Criminal Sanctions Enforcement (LCSE, in albanian LZSP), the convict admitted to the penitentiary facility undergoes an identity check including their accompanying documentation, and if they are in order, a handover report will be compiled (which includes his/her documentation and his/her personal belongings).

This report also includes the date of admission to the penal and correctional facility. According to Article 9, p.4, their finger prints are taken, their health condition is ascertained, several personal forms and records are filled out and then they are accommodated in the reception office or the observation center. The convicts should verify their knowledge of this regulation by placing their signature on the instruction log In addition, during this time, as mentioned above, the file of the convict is analyzed by the education service according to several methods; getting familiar with their personality, obtaining knowledge on their family and social setting, the crime they have committed, etc. It is also very crucial to obtain information whether or not the convict has any issues with another inmate in order to prevent it.

Having finished this brief observation, based on the data obtained, an observation file and a work program is compiled, as well as their individualized treatment. Therefore, each unit takes part in the observation and study of the convict; prepares a report on the future treatment of the convict. In this context, juvenile convicts, long-term convicts and recidivists are taken into consideration.

Based on what was said so far in relation to the observation of convicts at the penitentiary institutions in the Republic of Macedonia, it is obvious that this important stage of the penitentiary system is not given an appropriate caution. We believe that there should be certain supplements to the penitentiary acts, completion of staffing at the penal and correctional facilities with different experts of the scientific area so that this important stage is completed, at an appropriate level, at all penal and correctional facilities in the country. In addition, conditions should be ensured with the aim of a comprehensive study and observation of the convicts. Furthermore, given the significance of the scientific observation and study of the convicts, we are of the opinion that even in the Republic of Macedonia it would be very useful and important to establish an observation center with the aim of scientific observation of the convicts, which would enable to conduct research over the different categories of the convicts, based on previously set criteria.

\section{Conclusion}

Nowadays, the modern penology shows a great interest in the observation institutions because they are closer to the serving conditions of the punishment. However, there is a certain dilemma present here, too.

Based on what was said so far regarding the observation of convicts at the penitentiary institutions in the Republic of Macedonia, it is obvious that this important stage of the penitentiary system is not given an appropriate caution. We believe that there should be certain supplements to the penitentiary acts, completion of staffing at the penal and correctional facilities with different experts of the scientific area so that this important stage is completed, at an appropriate level, at all penal and correctional facilities in the country. Additionally, conditions should be ensured that these facilities apply more advanced scientific tools and methods with the aim of a comprehensive study and observation of the convicts. Furthermore, given the significance of the scientific observation and study of the convicts, we are of the opinion that even in the Republic of Macedonia it would be very useful and important to establish an observation center with the aim of scientific observation of the convicts, which would enable to conduct research over the different categories of the convicts, based on previously set criteria. 


\section{References}

Popoviç, V. Sistem izvrshenja kazni lishenja slobode u Jugoslaviji, Kralev, T. Penoloski leksikon. Skopje: NIP "Studentski zbor", 2002.

Gashi, R. Ekzekutimi i dënimit me burgim në Shqipëri, Prishtinë: 2001

Lamers, E. Die Offenen Gefaangnisse in der Nienderberg: Betrachtungen und Erfahrungen, Vutenberg: Kriminologije und Vollzug der Freicheitstrafe, Strasburg, 1961.

House rules of the Correctional Penitentiary Idrizovo, Skopje, May 2008 